\title{
Desempenho de quatro sistemas para compostagem de carcaça de aves ${ }^{1}$
}

\author{
Mônica S. S. de M. Costa ${ }^{2}$, Luiz A. de M. Costa ${ }^{3}$, Adilson Pelá4, Cesar J. da Silva ${ }^{5}$, Léo D. Decarlí \& Uilson F. Matter ${ }^{7}$
}

\begin{abstract}
RESUMO
Objetivou-se avaliar o desempenho de quatro sistemas para compostagem de carcaça de aves pelo monitoramento diário da temperatura, análise da presença ou ausência de Salmonella sp., contagem de coliformes totais (CT) e fecais (CF) e reciclagem de nutrientes. Os sistemas avaliados foram: Leira com aeração (LCA), Leira sem aeração (LSA), Composteira com aeração (CCA) e Composteira sem aeração (CSA). O processo de compostagem foi conduzido em dois estágios. No primeiro, as carcaças foram intercaladas com cama de aviário, palha e água. No segundo estágio, a massa de compostagem foi transferida para um pátio onde o material foi revolvido e umedecido semanalmente até a estabilização. Detectou-se a presença de Salmonella sp nos sistemas LSA e CSA ao final do primeiro estágio, desaparecendo após o segundo estágio. No composto, observou-se redução do número de CT e CF e dos teores de $\mathrm{N}$ e $\mathrm{C}$, além de acréscimo dos demais nutrientes. Concluiu-se a favor da realização da compostagem em qualquer um dos sistemas avaliados e importante realizar um segundo estágio da compostagem, tanto para eliminação de patógenos como para obtenção de um composto com melhores características agronômicas.
\end{abstract}

Palavras-chave: temperatura, Salmonella, coliformes totais e fecais, reciclagem de nutrientes

\section{Performance of four poultry carcasses composting systems}

\begin{abstract}
The aim of present study was to evaluate the performance of four poultry carcasses composting systems through daily temperature monitoring, in the absence and presence of Salmonella sp., total (TC) and faecal coliforms (FC) number and nutrients recycling. The evaluated systems were: Piles with aeration (1), Piles without aeration (2), Composters with aeration (3) and Composters without aeration (4). The process was carried out in two stages. The first stage was performed by arranging the carcasses with straw and water. In the second stage the compostage mass was transferred to a composting area where the material was revolved and wetted weekly until stabilization. The presence of Salmonella sp in the systems 2 and 4 at the end of the first stage was detected disappearing after the second one. In the compost a reduction in the number of TC and FC and of $\mathrm{N}$ and $\mathrm{C}$ contents as well as an increase in the rest of nutrients by the end of second stage was observed. It may be concluded that it is possible to perform the poultry carcass composting in anyone of the evaluated systems and is important to perform a second stage in the composting process to eliminate pathogens as well as to obtain a compost with better agronomic characteristics.
\end{abstract}

Key words: temperature, total and faecal coliforms, Salmonella sp., nutrient recycling

1 Pesquisa financiada pelo Programa RHAE/CNPq.

2 UNIOESTE, CEP 85960-000, Marechal Cândido Rondon-PR. Fone: (45)3254-3216,. E-mail:mssmc@superig.com.br

3 Doutor em Energia na Agricultura, CEP 85960-000, Marechal Cândido Rondon-PR. Fone: (45) 3254-3533, E-mail: Imendo@ig.com.br

${ }^{4}$ UEG, Rod. GO 330, Km 241 s/n, Anel Viário,CEP: 75400-000, Ipameri. Fone (64) 491556. E-mail: adilson.pela@ig.com.br

${ }^{5}$ UNEMAT, Rod. MT 208, Km 147/146, CEP: 78580-000, Alta Floresta, MT Fone: (66) 5214991. E-mail: silvacj@fcav.unesp.br

${ }^{6}$ Mestre em Produção Vegetal. E-mail: Idecarli@uol.com.br

${ }^{7}$ Doutor em Produção Vegetal. E-mail: uilsonfm@ig.com.br 


\section{INTRODUÇÃO}

A compostagem de carcaça de aves não é apenas uma tecnologia de baixo custo mas, sobretudo, de comprovada eficiência como forma de dispor adequadamente, no ambiente, a mortalidade diária que ocorre em galpões de frango de corte (Zanella, 1999), promovendo a reciclagem dos nutrientes contidos nas carcaças, eliminando agentes patogênicos e garantindo a biossegurança necessária para a atividade (Connor \& Blake, 1990; Atwell, 1995).

O processo de compostagem de carcaças de aves se enquadra na categoria de processos não convencionais de compostagem ou, segundo Kiehl (1985) processos especiais de compostagem. Deferida classificação se dá pelas características peculiares que este processo apresenta, sendo a principal o fato de ser realizado em dois estágios (Murphy, 1991; Blake \& Donald, 1992; Ancona \& Muñoz, 1994).

No primeiro estágio, as carcaças de aves são intercaladas com cama de aviário, palha (opcional) e água, para que, em condições de pouca aeração, ocorra sua decomposição, tornando-as menos agressivas ao manejo posterior no segundo estágio, pátio de compostagem, onde o material é propriamente compostado.

O primeiro estágio do processo de compostagem é, portanto, o ponto crítico para a biossegurança pois, no caso de um manejo inicial incorreto, seja pela mistura inadequada dos materiais (cama de aviário e água), ou pelo local inapropriado, pode-se promover condições ideais para o desenvolvimento de agentes patogênicos e a disseminação de doenças por vetores.

Entende-se, então, que os principais cuidados na compostagem de carcaça de aves dizem respeito aos procedimentos e ao local onde se realiza o primeiro estágio do processo. Quando transferido para o pátio de compostagem, o material, quando bem manejado no primeiro estágio, encontra-se menos agressivo ao manejo e o processo de compostagem toma suas características intrínsecas, isto é, realização de revolvimentos e regas freqüentes para que, em condições de aerobiose, os microrganismos decomponham o material até a produção final do composto.

As características estruturais do local onde a compostagem de carcaça de aves será realizada, são relevantes para o aspecto da biossegurança do processo (Zanella, 1999). A possibilidade de contaminação do solo e, posteriormente, das águas subterrâneas, preconiza a existência de um piso impermeável para conter a infiltração do chorume produzido durante o processo (Ritter \& Chirnside, 1995). A incidência de chuva sobre a leira de composto, além de provocar anaerobiose e formação de chorume (Silva et al., 1998) promove, também, perda de nutrientes (Nakagawa, 1992) havendo necessidade, portanto, da realização do processo em local coberto (Silva et al., 1997). Outro grande impasse da compostagem de carcaças de aves reside no ataque de animais domésticos ou silvestres, visto que eles revolvem as leiras em busca das carcaças para alimentação, sendo grandes disseminadores de doenças (Zanella, 1999), havendo necessidade de proteger o local onde será realizado o primeiro estágio da compostagem, através da utilização de telas ou outro artifício.
No que diz respeito aos procedimentos necessários para garantir uma eficiência do processo de compostagem em seu primeiro estágio enfatiza-se a proporção entre os materiais a serem compostados (carcaça de aves: cama de aviário: água) e a presença de oxigênio nesta fase (Zanella, 1999).

Objetivou-se, neste trabalho, avaliar o desempenho de quatro sistemas para compostagem de carcaça de aves (leiras e composteiras com e sem aeração), através do monitoramento diário da temperatura, determinação do tempo de compostagem e da redução em piso de material compostado; avaliação da presença ou ausência de Salmonella sp., contagem de coliformes totais e fecais e análise da composição química do material e reciclagem de nutrientes pelo processo.

\section{MATERIAL E MÉTODOS}

A pesquisa foi desenvolvida pela UNIOESTE - Campus de Marechal Cândido Rondon, PR, em área localizada a 24 33' 40” S, 54 04' 12” W e 420 m de altitude média, com temperaturas médias variando entre 14 e $28^{\circ} \mathrm{C}$.

Foram definidos quatro sistemas para compostagem de carcaça de aves, a saber: Leira com aeração (LCA), Leira sem aeração (LSA), Composteira com aeração (CCA) e Composteira sem aeração (CSA). As leiras foram confeccionadas em um barracão em desuso, coberto, com piso em cimento e paredes nas laterais e no fundo, sendo a parte da frente sem parede, porém protegida com portão de tela para evitar entrada de animais. Para LCA introduziu-se, no interior da massa de compostagem e durante a sua montagem, um tubo de PVC de $100 \mathrm{~mm}$ de diâmetro perfurado em sua extensão horizontal e em forma de "U”, para que ocorresse o efeito chaminé e, assim, promover maior troca gasosa no interior da leira. O tubo foi instalado a aproximadamente $20 \mathrm{~cm}$ da base da leira, ficando em meio à massa de compostagem. A LSA não recebeu qualquer estrutura que favorecesse a circulação de ar no interior da massa de compostagem.

As composteiras utilizadas foram construídas em alvenaria nas dimensões de 4,5 x 6,0 m e com pé direito de 2,0 $\mathrm{m}$ de altura. A estrutura foi dividida por uma parede de alvenaria, em duas partes, e estas, por sua vez, foram divididas em três compartimentos com capacidade para $6 \mathrm{~m}^{3}$, separados por tábuas de madeira, com remoção em forma de comporta (sem aeração) ou por paredes de alvenaria perfuradas (com aeração). Para as CCA's instalaramse, no centro dos compartimentos das extremidades, tubos de PVC de 200 mm de diâmetro, perfurados, atravessando o telhado e com exaustores eólicos nas extremidades superiores. As paredes laterais foram construídas com meios tijolos vazados de seis furos; as tábuas frontais (móveis) também foram perfuradas para facilitar a aeração da massa de compostagem. As CSA's não receberam qualquer estrutura que favorecesse a circulação de ar no interior da massa de compostagem (Figura 1).

Cada sistema foi abastecido com a totalidade da mortalidade de um aviário, durante um ciclo de engorda. A 


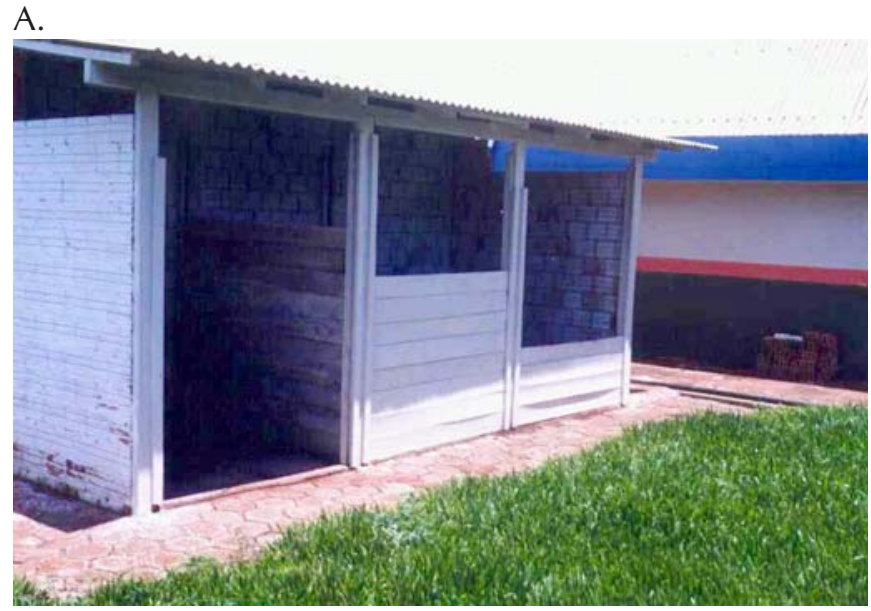

B.

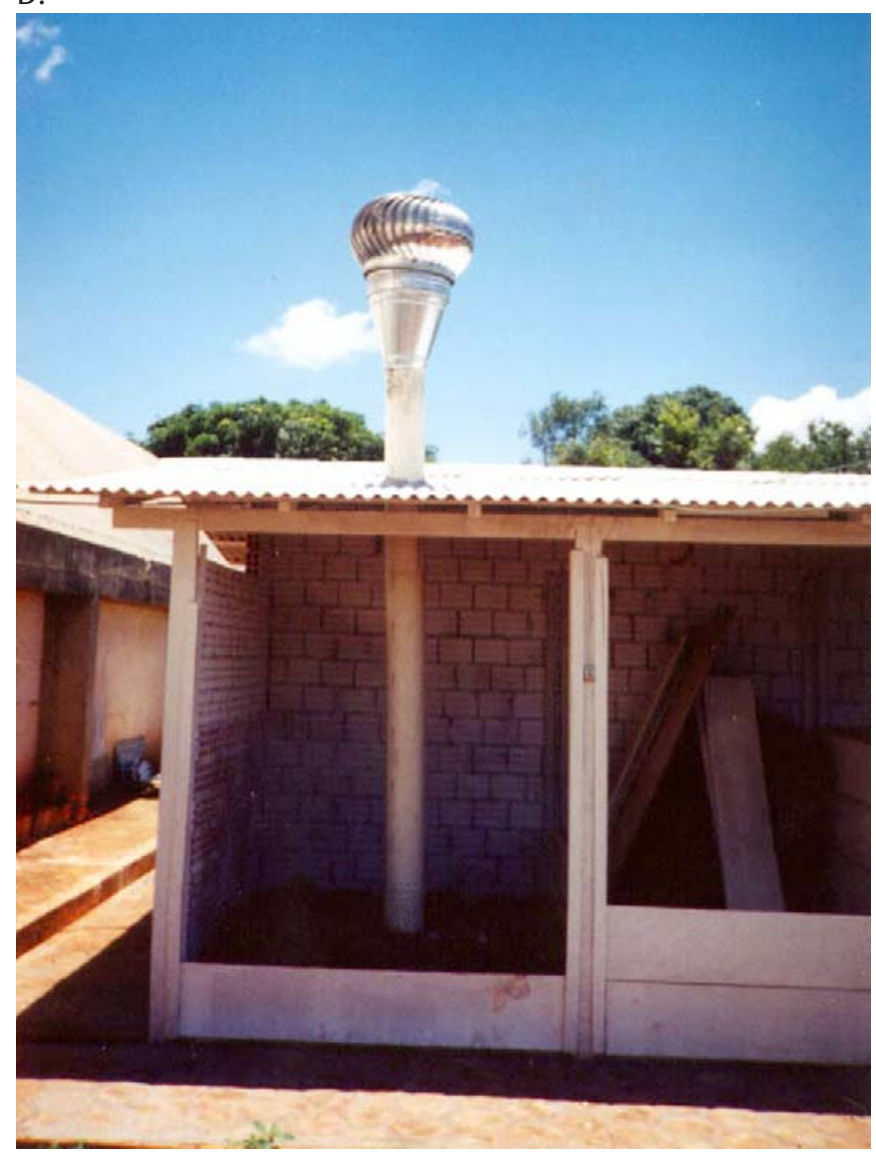

Figura 1. Composteira sem (A) e com (B) aeração

proporção entre carcaça e cama de aviário, foi de 1:3, ou seja, para cada quilo de carcaça foram adicionados três quilos de cama de aviário. A quantidade de água adicionada foi de $10 \%$ referente ao peso da cama de aviário, isto é, para cada quilo de cama de aviário adicionaram-se $100 \mathrm{~mL}$ de água.

A disposição dos materiais nos sistemas se deu da seguinte maneira: de início, depositou-se uma camada de aproximadamente $20 \mathrm{~cm}$ de cama de aviário; diariamente, foram sendo confeccionadas camadas intercalando palha de aveia, carcaça de aves, metade da quantidade de cama de aviário, água e o restante da cama de aviário, sempre nesta seqüência, de maneira que a superfície permanecesse sempre seca, evitando a ovoposição pelas moscas.

As camadas nas leiras foram sendo confeccionadas até uma altura de 1,5 m, para garantir a estabilidade da estrutura, enquanto nas composteiras o material foi intercalado até aproximadamente 1,8 m. Diariamente, monitorou-se a temperatura ambiente e a temperatura da massa de compostagem, em seis pontos, em cada sistema, com auxílio de termômetro digital e haste de $30 \mathrm{~cm}$. Para fins de análise de dados considerou-se a média semanal das temperaturas em cada sistema. Ao final do abastecimento de cada sistema e na última camada, adicionou-se $1 \mathrm{~L}$ de substrato contendo bactérias do gênero Salmonella sp, na diluição de $10^{8}$ unidades por $\mathrm{mL}$.

O tempo em que a massa de compostagem permaneceu no primeiro estágio, antes de ser transferida para o pátio de compostagem (segundo estágio do processo), variou de acordo com a quantidade de carcaça adicionada em cada sistema, ou seja, da porcentagem de mortalidade do lote e da idade dos animais. No caso de animais mais velhos, cujas carcaças são maiores, é mais seguro que este material permaneça por mais tempo no primeiro estágio, para garantir que o material que será manipulado não esteja tão agressivo e possa ser transferido para o pátio de compostagem com o mínimo impacto possível. No pátio de compostagem realizaram-se revolvimentos semanais seguidos de pesagem e adição de água, para atingir 60\% de umidade; após atingir a estabilização, o material foi novamente pesado, calculada a umidade e ensacado.

As análises da composição química do material, colimetria e presença ou ausência de Salmonella sp., foram realizadas em amostras coletadas em duas situações: no final do primeiro estágio e no final do segundo estágio.A porcentagem de $\mathrm{C}$ orgânico foi determinada pelo método de Walkley-Black (1944) apud Kiehl (1985); para determinação de N e P realizou-se digestão sulfúrica para obtenção do extrato, conforme metodologia descrita por Tedesco et al. (1985) e, para os nutrientes $\mathrm{K}$, Ca e Mg, o extrato foi obtido através da digestão com $\mathrm{HCl}$ e peróxido de hidrogênio, seguindo-se metodologias descritas pelos mesmos autores. A determinação do $\mathrm{pH}$ em $\mathrm{H}_{2} \mathrm{O}$ se deu conforme descrito por Kiehl (1985). A determinação da ausência ou presença de Salmonella sp foi realizada pelo Método do Plaqueamento Diferencial e as determinações de coliformes totais e fecais pela técnica do Número Mais Provável (NMP), ambas realizadas pelo Laboratório de Microbiologia da Sadia, em Toledo, PR.

\section{RESULTADOS E DISCUSSÃO}

O monitoramento diário da temperatura permitiu que se confeccionassem figuras considerando-se as médias semanais para cada sistema avaliado (Figura 2).

Comparando-se, inicialmente, os valores médios de temperatura entre os dois estágios para cada sistema observase, de maneira geral, aumento de temperatura no segundo estágio, quando comparado com o primeiro, independente do sistema analisado, cujo fato pode ser explicado pela maior 


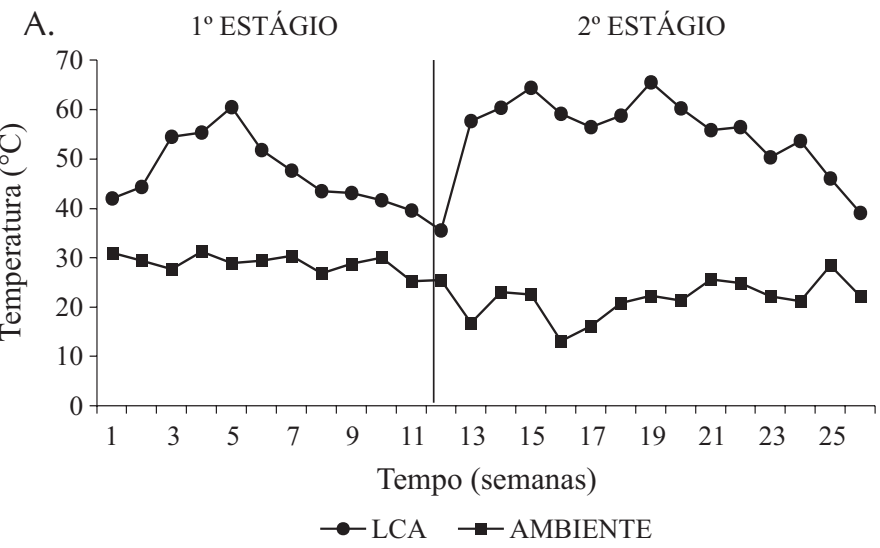

B.

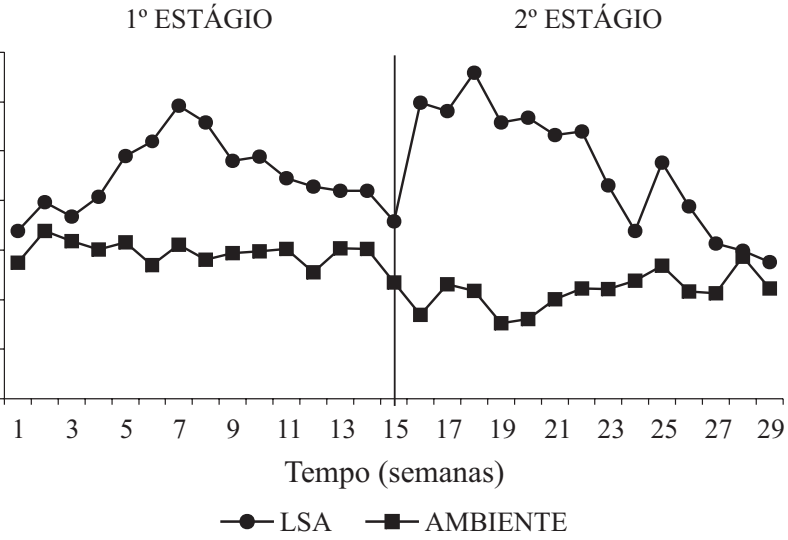

C. $1^{\circ}$ ESTÁGIO

$2^{\circ}$ ESTÁGIO

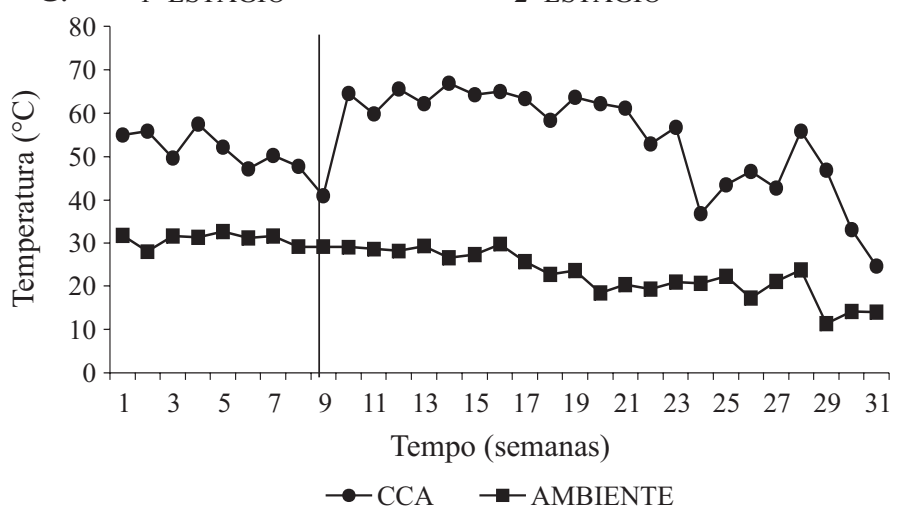

D.

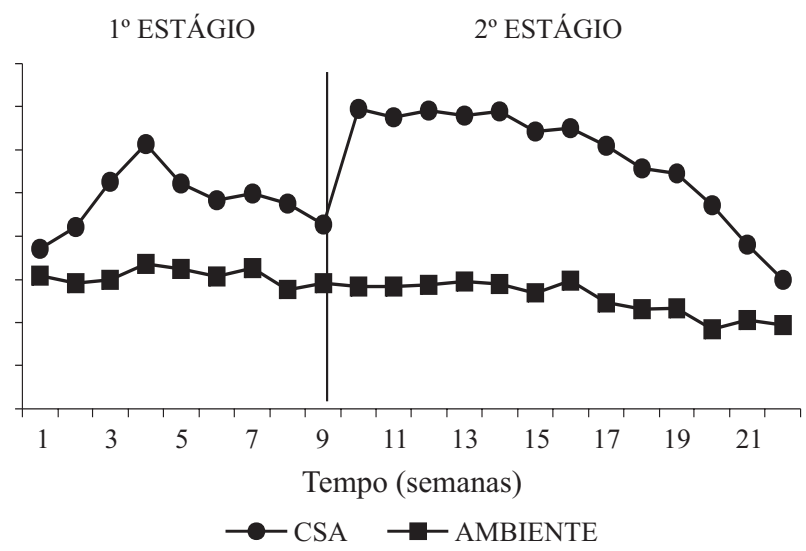

Figura 2. Monitoramento da temperatura nos sistemas LCA (A), LSA (B), CCA (C) e CSA (D), em relação à temperatura ambiente, nos dois estágios do processo

aeração existente no segundo estágio, em que os revolvimentos foram realizados com freqüência e a umidade mantida em torno de 60\%. Referidas condições, consideradas ótimas para o desenvolvimento microbiano aeróbio (Kiehl, 1985; Peixoto, 1988 e Pereira Neto, 1994), possibilitaram aumento da temperatura, parâmetro desejável na compostagem de carcaça de aves, pois contribuem para a eliminação de agentes patogênicos (Atwell, 1995). Turner (2002) comenta que resultados obtidos em experimentos com compostagem demostraram o crescimento de coliformes em leiras quando o processo foi conduzido a temperaturas mesofílicas; assim, cuidados devem ser tomados para manter a compostagem do material de forma adequada, ao contrário de simplesmente deixar a leira sem monitoramento.

Pode-se observar, também, semelhança no comportamento da temperatura, tanto nos sistemas com aeração como nos sistemas sem aeração, no primeiro estágio do processo. A presença de aeração no primeiro estágio, dadas as condições limitantes do processo nesta fase, deveria permitir uma redução do tempo de compostagem, ou seja, uma aceleração do processo, impedindo aumentos expressivos da temperatura (Costa et al., 2005); entretanto, os valores de temperatura foram semelhantes nos quatro sistemas avaliados e o tempo de compostagem parece não ter sofrido alteração, dadas as condições impostas, que refletiriam no tempo de compostagem no segundo estágio (Tabela 1).

Ao final do processo, a porcentagem de redução do material foi maior nos sistemas que permaneceram por mais tempo em compostagem. Neste aspecto, Gorgati (2001) avaliando o processo de compostagem em resíduos sólidos urbanos obteve, em média, uma redução de $47 \%$ no peso do material após o processo, tanto em leiras cobertas como nas descobertas. Amorim (2002) trabalhando com esterco de caprinos observou que, apesar de haver diferenças nas reduções dos volumes $\left(\mathrm{m}^{3}\right)$ ocupados, maiores em leiras conduzidas durante o verão e outono (médias de 68,0 e 67,7\%,

Tabela 1. Características físicas dos sistemas durante os dois estágios do processo de compostagem

\begin{tabular}{|c|c|c|c|c|c|c|c|c|}
\hline \multirow{2}{*}{ Sistemas* } & \multicolumn{2}{|c|}{ Peso seco } & \multirow{2}{*}{ Redução (\%) } & \multicolumn{3}{|c|}{ Tempo Compostagem (dias) } & \multicolumn{2}{|c|}{ Maior temperatura $\left({ }^{\circ} \mathrm{C}\right)$} \\
\hline & Inicial (kg) & Final (kg) & & $1^{0}$ Estágio & $2^{0}$ Estágio & total & $1^{0}$ Estágio & $2^{0}$ Estágio \\
\hline LCA & 2299 & 496 & 78,4 & 175 & 108 & 283 & 60,5 & 65,5 \\
\hline LSA & 520 & 245 & 52,9 & 142 & 108 & 250 & 59,2 & 65,9 \\
\hline CCA & 1569 & 888 & 43,4 & 101 & 153 & 254 & 57,4 & 66,9 \\
\hline CSA & 439 & 346 & 21,2 & 83 & 92 & 175 & 61,3 & 69,3 \\
\hline
\end{tabular}

*LCA - Leira com aeração, LSA - Leira sem aeração, CCA - composteira com aeração, CSA - composteira sem aeração 
respectivamente) se comparadas com as de inverno e primavera (médias de 64,1 e 65,1\%, respectivamente) a tendência linear de diminuição do volume foi a mesma em todas as estações, porém, para fins de avaliação do desempenho do sistema de compostagem visando à biossegurança, os aspectos microbiológicos são os mais importantes. Na Tabela 2 estão relacionados os parâmetros microbiológicos analisados.

Tabela 2. Parâmetros microbiológicos avaliados no material, ao final dos primeiro e segundo estágios do processo de compostagem

\begin{tabular}{ccccc}
\hline $\begin{array}{c}\text { Sistemas* } \\
\text { EStágio }\end{array}$ & $\begin{array}{c}\text { Salmonella sp } \\
\text { LCA }\end{array} 1^{0}$ & $\begin{array}{c}\text { Coliformes Totais } \\
\left(\mathbf{U F C} \mathbf{~ g}^{-1} \text { ) }\right.\end{array}$ & $\begin{array}{c}\text { Coliformes Fecais } \\
\left(\mathbf{U F C} \mathbf{~ g}^{-1} \text { ) }\right.\end{array}$ \\
\hline LCA & $2^{0}$ & Ausente & 24 & 12 \\
LSA & $1^{0}$ & Presente & $1,42 \times 10^{2}$ & 12 \\
LSA & $2^{0}$ & Ausente & 46 & 10 \\
CCA & $1^{0}$ & Ausente & 18 & 10 \\
CCA & $2^{0}$ & Ausente & 10 & 18 \\
CSA & $1^{0}$ & Presente & $6,0 \times 10^{3}$ & $7,2 \times 10^{3}$ \\
CSA & $2^{0}$ & Ausente & 10 & 10 \\
\hline
\end{tabular}

*LCA - Leira com aeração, LSA - Leira sem aeração, CCA - composteira com aeração, CSA - composteira sem aeração

Detectou-se, nos sistemas LSA e CSA a presença da Salmonella sp ao se transferir a massa de compostagem do primeiro para o segundo estágio. É conveniente salientar que a aeração é apenas um fator interferente neste processo, o que impede de se concluir sobre o seu efeito no desenvolvimento deste patógeno, na situação estudada, mas o que se pode afirmar, com certeza, é que a realização de um segundo estágio no processo de compostagem de carcaça de aves é imprescindível. São as condições de aeração e umidade presentes na compostagem do segundo estágio que garantem a eliminação dos agentes patogênicos e a redução do número de coliformes totais e fecais, indicativos do potencial poluente do material (Tiquia et al., 1998; Contreras-Ramos et al., 2004; Manios \& Stentiford, 2004).

Os valores de CT e CF encontrados podem ser comparados a outros descritos na literatura consultada. Embora se refiram a outros tipos de resíduos e processos, podem servir como referência para comparação.

Vuorinen \& Saharinen (1997) comentam que a densidade de coliformes fecais para higienização é de $10^{3}$ UFC g- $^{-1}$ de sólidos, pois a Salmonella é considerada ausente em amostras que contêm quantidades de coliformes fecais menores que esta, segundo Farrell (1992) citado pelos autores. Neste aspecto, ressaltam-se duas situações: a primeira, com relação à presença de Salmonella no primeiro estágio da LSA, mesmo com um número de CF menor que $10^{3} \mathrm{UFC} \mathrm{g}^{-1}$ sólidos. Por outro lado, no caso da CSA, o processo de compostagem promoveu diminuição dos valores de CF, o que impediu a proliferação Salmonella.

A diminuição dos valores de CF durante o processo de compostagem é também constatada em outros trabalhos. Segundo Hassen et al. (2001), a presença de coliformes é, de modo geral, utilizada como indicador da qualidade sanitária em amostras de solos e água. Em seu trabalho, os autores detectaram a presença de $2,5 \times 10^{7} \mathrm{UFC} \mathrm{g}^{-1}$ amostra seca no início do processo de compostagem de resíduos sólidos municipais, diminuindo para 7,9 x $10^{3}$ durante a fase termofílica. Pagilla et al. (2000) em estudo desenvolvido com esterco suíno submetido a processos aeróbios e anaeróbios de tratamento, constataram redução na densidade de coliformes fecais de $7,1 \times 10^{8} \mathrm{NMP} \mathrm{g}^{-1}$ sólidos totais para menos de $10^{3} \mathrm{NMP}^{-1}$ sólidos totais nos tratamentos aeróbios, enquanto o digestor anaeróbio não pode reduzi-lo a menos de $10^{5} \mathrm{NMP} \mathrm{g}^{-1}$ sólidos totais. Kherrati et al. (1998) trabalhando com o aproveitamento de resíduos de frigorífico pelo processo de silagem, obtiveram uma contagem de CT variando de $7,0 \times 10^{3}$ a $7,0 \times 10^{6}$ no material "in natura", para menos de 1 UFC g ${ }^{-1}$ no produto. Da mesma forma, a contagem de CF oscilou de 4,0 x $10^{3}$ a $1,0 \times 10^{6} \mathrm{UFC} \mathrm{g}^{-1}$ no material "in natura" para menos de $1 \mathrm{UFC} \mathrm{g}^{-1}$, no produto final.

Considera-se, portanto, que a principal característica ou finalidade do primeiro estágio está em transformar, de maneira segura, um material de difícil manejo (carcaças de aves) em um material que possa ser manipulado em um processo posterior de compostagem propriamente dito; desta forma e independente da condição de aeração no primeiro estágio, a transferência do material para o pátio de compostagem e a realização de revolvimentos e regas freqüentes, garantem condições de biossegurança ao processo (Blake \& Donald, 1992). Outro benefício do segundo estágio no processo de compostagem de carcaça de aves está na maior reciclagem dos nutrientes, proporcionada pela realização desta etapa. A Tabela 3 apresenta os teores dos nutrientes encontrados no material ao final dos primeiro e segundo estágios do processo.

Tabela 3. Composição química do material ao final do primeiro e do segundo estágios do processo de compostagem

\begin{tabular}{|c|c|c|c|c|c|c|c|c|}
\hline \multirow{2}{*}{ SISTEMAS* } & \multirow{2}{*}{ ESTÁGIO } & C & $\mathbf{N}$ & $\mathbf{P}$ & K & \multirow{2}{*}{$\begin{array}{c}\mathrm{pH} \\
\mathrm{H}_{2} \mathrm{O}\end{array}$} & $\mathrm{Ca}$ & $\mathrm{Mg}$ \\
\hline & & \multicolumn{2}{|c|}{$(\%)$} & \multicolumn{2}{|c|}{$\mu \mathbf{g} \mathbf{g}^{-1}$} & & \multicolumn{2}{|c|}{$\mu \mathrm{g} \mathrm{g}^{-1}$} \\
\hline LCA & $1^{0}$ & 34,2 & 3,85 & 19.200 & 17.600 & 6,97 & 18.150 & 4.400 \\
\hline LCA & $2^{0}$ & 27,5 & 2,45 & 23.675 & 32.800 & 7,89 & 28.200 & 7.425 \\
\hline LSA & $1^{0}$ & 36,5 & 3,15 & 15.800 & 17.600 & 7,09 & 21.000 & 4.800 \\
\hline LSA & $2^{0}$ & 25,3 & 2,45 & 31.500 & 32.600 & 7,13 & 31.350 & 8.350 \\
\hline CCA & $1^{0}$ & 37,3 & 3,5 & 19.713 & 16.000 & 7,47 & 20.400 & 4.700 \\
\hline CCA & $2^{0}$ & 30,6 & 3,5 & 30.125 & 25.600 & 7,87 & 61.200 & 7.500 \\
\hline CSA & $1^{0}$ & 36,1 & 2,8 & 15.563 & 15.600 & 7,57 & 23.550 & 5.550 \\
\hline CSA & $2^{0}$ & 25,0 & 2,1 & 22.225 & 16.000 & 7,63 & 30.250 & 6.150 \\
\hline \multicolumn{2}{|c|}{ Média $2^{\circ}$ estágio } & 27,1 & 2,6 & 26.881 & 26.750 & 7,63 & 37.750 & 7.356 \\
\hline
\end{tabular}

*LCA - Leira com aeração, LSA - Leira sem aeração, CCA - composteira com aeração, CSA - composteira sem aeração 
Conforme se esperava, ocorreram reduções dos teores de N e C, em razão das perdas por volatilização e respiração, respectivamente (Tiquia \& Tam, 2002) e acréscimos nos teores dos demais nutrientes, devido à disponibilização ocorrida pela ação microbiana no material (Kiehl, 1985).

Analisando-se a composição química média dos compostos produzidos ( $2^{\circ}$ estágio) a partir da compostagem de carcaça de aves, $\mathrm{pH}\left(\mathrm{H}_{2} \mathrm{O}\right)=7,63 \mathrm{C}(\%)=27,1 ; \mathrm{N}(\%)=2,6$; $\mathrm{P}\left(\mu \mathrm{g} \mathrm{g}^{-1}\right)=26881 ; \mathrm{K}\left(\mu \mathrm{g} \mathrm{g}^{-1}\right)=26750 ; \mathrm{Ca}\left(\mu \mathrm{g} \mathrm{g}^{-1}\right)=37750$; $\operatorname{Mg}\left(\mu g^{-1}\right)=7356$, pode-se compará-la com a composição de outros compostos relatados na literatura. Silva et al. (1998) trabalhando com compostagem de resíduos sólidos de frigorífico, obteve a seguinte composição média para o composto: $\mathrm{pH}\left(\mathrm{CaCl}_{2}\right)=7,1 \mathrm{C}(\%)=26,7 ; \mathrm{N}(\%)=2,5 ; \mathrm{P}\left(\mu \mathrm{g} \mathrm{g} \mathrm{g}^{-1}\right)=7100$; $\mathrm{K}\left(\mu \mathrm{g} \mathrm{g}^{-1}\right)=9700 ; \mathrm{Ca}\left(\mu \mathrm{g} \mathrm{g}^{-1}\right)=7600 ; \mathrm{Mg}\left(\mu \mathrm{g} \mathrm{g}^{-1}\right)=1900$. Costa et al. (2005) trabalhando com compostagem de resíduos sólidos da indústria de desfibrilação de algodão, obteve a seguinte composição média para o composto pronto: $\mathrm{pH}\left(\mathrm{H}_{2} \mathrm{O}\right)=7,9 ; \mathrm{C}(\%)=20,8 ; \mathrm{N}(\%)=2,7 ; \mathrm{P}\left(\mu \mathrm{g} \mathrm{g}^{-1}\right)=3554$; $\mathrm{K}\left(\mu \mathrm{g} \mathrm{g}{ }^{-1}\right)=20400 ; \mathrm{Ca}\left(\mu \mathrm{g} \mathrm{g}{ }^{-1}\right)=25827 ; \mathrm{Mg}\left(\mu \mathrm{g} \mathrm{g}^{-1}\right)=4625$.

Esta comparação permite inferir-se sobre os elevados teores de P, K, Ca e Mg encontrados no composto de carcaça de aves, porém sua utilização dependerá da cultura que irá recebê-lo e da capacidade suporte do ambiente. Em virtude da grande quantidade de $\mathrm{P}$, quase quatro vezes maior que o composto de resíduos de frigorífico e 7,5 vezes maior que o resíduo de algodão, deve-se atentar para a quantidade de composto a ser aplicado, visando diminuir os riscos de impacto ambiental, principalmente de contaminação das águas.

Burin (2002) ao avaliar os efeitos da utilização de cama de aviário, composto de carcaça de aves e adubação mineral, comparados com uma testemunha, nas propriedades químicas e físicas do solo e na produtividade de feijão, observou que, apesar das melhorias nos atributos avaliados quando se utilizou o composto de carcaça de aves, a quantidade de $\mathrm{P}\left(\mathrm{mg} \mathrm{dm}^{-3}\right.$ ) passou de 4,24 para 303,7 durante o experimento (novembro/1999 a novembro/2000) após três aplicações do composto $\left(30 \mathrm{t} \mathrm{ha}^{-1}\right)$ distribuídas respectivamente na cultura de sorgo e duas safras consecutivas de feijão. Infere-se, portanto, que a composição química dos compostos orgânicos produzidos está diretamente relacionada com o material de origem e que sua utilização como fonte de nutrientes e de matéria orgânica às culturas, requer um estudo da capacidade de suporte do ambiente visando garantir nutrição às plantas sem, no entanto, comprometer os recursos naturais.

A análise conjunta dos resultados obtidos nos três parâmetros avaliados (físicos, microbiológicos e químicos) permite inferir sobre o desempenho positivo dos quatro sistemas de compostagem de carcaça de aves. De maneira geral, pode-se realizar o primeiro estágio da compostagem de carcaça de aves tanto em leiras, visando à utilização de uma estrutura existente na propriedade, como em um barracão provido de piso impermeável, cobertura e proteção contra o ataque de animais, e em composteiras construídas para atender a esta finalidade; entretanto, além do local, outros cuidados no que diz respeito à metodologia propriamente dita da compostagem, devem ser tomados, como uma relação adequada entre cama de aviário: carcaça de aves: água. De qualquer maneira, a realização de um segundo estágio na compostagem de carcaça de aves, faz-se necessário, sobretudo no que diz respeito à biossegurança do processo.

\section{CONCLUSÕES}

1. O desempenho dos quatro sistemas para compostagem de carcaça de aves avaliados nesta pesquisa foi satisfatório.

2. A realização de um segundo estágio na compostagem de carcaça de aves é imprescindível para garantir a eliminação de agentes patogênicos de interesse e para a produção de um composto com melhores características agronômicas.

3. Com relação à aeração no primeiro estágio do processo, outros estudos devem ser conduzidos com vistas a avaliar seu efeito, tanto na eliminação de patógenos como na diminuição do tempo de compostagem.

\section{AgRADECIMENTOS}

Os autores agradecem ao Programa CNPq/RHAE, pelo apoio na formação de recursos humanos. Às empresas do setor avícola Sadia S.A, COPACOL e COOPERVALE, pelo apoio financeiro e pela realização das análises laboratoriais. À Agrícola Horizonte, pela cessão da área onde foi realizado o experimento. À Universidade Estadual do Oeste do Paraná - Campus de Marechal Cândido Rondon, PR, pelo apoio e incentivo à pesquisa. À Faculdade de Ciências Agrárias e Veterinárias - FCAV/UNESP, pela parceria. Aos Professores Dr. Jorge de Lucas Jr. e Dra. Tânia M. Baptista dos Santos, pelos conhecimentos repassados, pelo apoio, dedicação e amizade.

\section{LITERATURA CITADA}

Amorim, A. C. Caracterização dos dejetos de caprinos: reciclagem energética e de nutrientes. Jaboticabal: UNESP, 2002. 108p. Dissertação Mestrado

Ancona, L. H.; Muñoz, R. Elaboración de una composta com subproductos avícolas. Industria Avicola, Bogotá, v.41, n.3, p.18-20, 1994.

Atwell, J. K. Mortalities disposal: is your farm bio-secure? Broiler Industry, Mount Morris, v.58, n.6, p.36, 1995.

Blake, J. P.; Donald, J. O. Alternatives for the disposal of poultry carcasses. Poultry Science, Champaign, v.71, n.7, p.11301135, 1992.

Burin, A. Desenvolvimento do sorgo granífero (sorghum bicolor) e do feijão (phaseolus vulgaris) em resposta a diferentes adubações (orgânica e mineral). Marechal Cândido Rondon: UNIOESTE, 2002. 76p. Trabalho de Graduação

Connor, D. E.; Blake, J. P. Microbial changes asociated with composting of poultry farm mortalities. Poultry Science, Champaign, v.69, n.1, p. 36, 1990. 
Contreras-Ramos, S. M.; Alvarez-Bernal, D.; Trujillo-Tapia, N.; Dendoove, L. Compost of tannery effluent with cow manure and wheat straw. Bioresource Technology, Barking, v.94, n.2, p.223-228, 2004.

Costa, M. S. S. de M.; Costa, L. A. de M.; Sestak, M.; Olibone, D.; Sestak, D.; Kaufmann, A. V.; Rotta, S. R. Compostagem de resíduos da indústria de desfibrilação de algodão. Engenharia Agrícola, Jaboticabal, v.25, n.2, p.540-548, 2005.

Gorgati, C. Q. Resíduos sólidos urbanos em área de proteção aos mananciais - município de São Lourenço da Serra - SP: compostagem e impacto ambiental. Botucatu: UNESP, 2001. 82p. Tese Doutorado

Hassen, A.; Belguith, K.; Jedidi, N.; Cherif, A.; Cherif, M.; Boudabous, A. Microbial characterization during composting of municipal solid waste. Bioresource Technology, Barking, v.80, n.3, p.217-25, 2001.

Kherrati, B.; Faid, M.; Elyachioui, M.; Wahmane, A. Process for recycling slaughterhouses wastes and by-products by fermentation. Bioresource Technology, Barking, v.63, n.1, p.75-79, 1998.

Kiehl, E. J. Fertilizantes orgânicos. 1.ed. Piracicaba: Agronômica Ceres, 1985. 492p.

Manios, T.; Stentiford, E. I. Sanitary aspect of using partially treated landfill leachate as a water source in green waste composting. Waste Management, Amsterdam, v.24, n.1, p 107110, 2004.

Murphy, D.W. Dead birds disposal methods still high research priority. Poultry Digest, Mount Morris, v.50, n.1, p.34-38, 1991.

Nakagawa, J. Compostagem: obtenção e uso. In: Encontro sobre Matéria Orgânica do Solo: Problemas e Soluções, 1, 1992, Botucatu. Anais... Botucatu: Champion Papel e Celulose Ltda., 1992. p.159-88.

Pagilla, K.; Kim, H.; Cheunbarn, T. Aerobic thermophilic and anaerobic mesophilic treatment of swine waste. Water Research, Exceter, v.34, n.10, p.2747-53, 2000.

Peixoto, R. T. G. Compostagem: opção para o manejo orgânico do solo. Londrina: IAPAR, 1988. 53p.
Pereira Neto, J. T. Tratamento, reciclagem e impacto ambiental de dejetos agrícolas. In: Conferência Sobre Agricultura e Meio Ambiente, 1, 1992, Viçosa. Anais... Viçosa: UFV-NEPEMA, 1994. p.61-74.

Ritter, W. F.; Chirnside, A. E. M. Impact of dead bird disposal pits on ground-water quality on the Delmarva Peninsula. Bioresource Technology, Barking, v.53, n.2, p.105-111, 1995.

Silva, M. S.; Costa, L. A. de M.; Vilas Boas, M. A.; Silva, M. S. Compostagem de resíduos sólidos de frigorífico visando o saneamento ambiental e a produção de adubo orgânico. In: Congresso Brasileiro de Ciência do Solo, 25, 1997, Rio de Janeiro. Anais... Viçosa: SBCS, 1997. CD Rom.

Silva, M. S.; Costa, L. A. de M.; Decarli, D. L.; Pelá, A.; Zucareli, C.; Silva, C. J. da.; Matter, U. F.; Santos, J. S. Desenvolvimento de metodologia para compostagem de resíduos sólidos de frigorífico. In: Congresso Brasileiro de Engenharia Agrícola, 27, 1998, Poços de Caldas. Anais... Jaboticabal: SBEA, 1998, v.1, p.52-54

Tedesco, M. J.; Volkweiss, S. J.; Bohnen, H. Análises de solo, plantas e outros materiais. Porto Alegre: UFRGS, 1985. 188p. Boletim técnico, 5

Tiquia, S. M.; Tam, N. F. Y. Characterization and composting of poultry litter in forced aeration piles. Process Biochemistry, Elsevier, v.37, n.8, p.869-880, 2002.

Tiquia, S. M.; Tam, N. F. Y.; Hodgkiss, I. J. Salmonella elimination during composting of spent pig litter. Bioresource Technology, Barking, v.63, n.2, p.193-196, 1998.

Turner, C. The thermal inactivation of Escherichia. coli in straw and pig manure. Bioresource Technology, Barking, v.84, n.1, p.57-61, 2002.

Vuorinen, A. H.; Saharinen, M. H. Evolution of microbiological and chemical parameters during manure and straw co-composting in a drum composting system. Agriculture, Ecosystems and Environment, Amsterdam, v.66, n.1, p.19-29, 1997.

Zanella, J. C. Alternativa ecológica. Avicultura Industrial, São Paulo, v.89, n.1067, p.60-63, 1999. Informe Técnico. 